\title{
Proceeding
}

Supplementary Issue: Summer Conferences of Sports Science. Costa Blanca Sports Science Events, 25-26 September 2020. Alicante, Spain.

\section{Use of didactic-technological resources in the didactic discipline of physical education in time of pandemic}

\author{
AMINADAN LAÍNEZ-BONILLA ${ }^{1}$, LIDA DE LA CARIDAD SÁNCHEZ-RAMÍREZ², JOSÉ ELIAKIN LAÍNEZ- \\ BONILLA ${ }^{1}$, NAHUN DAVID MARTÍNEZ-SARAVIA ${ }^{1}$ \\ ${ }^{1}$ National Autonomous University of Honduras, Tegucigalpa, Honduras \\ 2University of Oriente, Santiago de Cuba, Cuba
}

\begin{abstract}
In recent years, the incessant advance of technology does not seem to be holding back, the challenge of educational centres and particularly of universities and specifically the National Autonomous University of Honduras, lies in preparing as an institution and in turn preparing its students to adapt to changes quickly and effectively, with a minimum expenditure of human and material resources. Thus, in the sports educational field, awareness must be gained that the use of technological resources imposes marked transformations in the configuration of the pedagogical process, with changes in the roles that the various actors have been playing. Hence, the objective is focused on exemplifying the use of a didactic-technological resource in the Didactic discipline of Physical Education in times of pandemic. This study was carried out with a qualitative methodology, established in case studies through the opinions obtained from teachers, coaches and students. The sample consisted of 22 professors and 15 students from the Physical Culture career in the 2020 academic year. Descriptive statistics (frequencies and percentages) are used for data processing, the variables are on an ordinal scale. It is confirmed that the use of didactic-technological resources used in a synchronous and asynchronous way allows the transmission and appropriation of information, experimentation, training by the student, which favours both learning and research training in sport without the space and time constitute barriers to achieving this.
\end{abstract}

Keywords: Didactics; Research; Pedagogical process.

\section{Cite this article as:}

Laínez-Bonilla, A., Sánchez-Ramírez, L.C., Laínez-Bonilla, J.E., \& Martínez-Saravia, N.D. (2020). Use of didactictechnological resources in the didactic discipline of physical education in time of pandemic. Journal of Human Sport and Exercise, 15(4proc), S1476-S1487. doi:https://doi.org/10.14198/ihse.2020.15.Proc4.44

Corresponding author. National Autonomous University of Honduras, 11101 Tegucigalpa, Honduras. http://orcid.org/00000001-5543-6328

E-mail: aminadan.bonilla@unah.edu.hn

Abstract submitted to: Spring Conferences of Sports Science. Costa Blanca Sports Science Events, 19-20 June 2020. Alicante, Spain.

JOURNAL OF HUMAN SPORT \& EXERCISE ISSN 1988-5202

(c) Faculty of Education. University of Alicante

doi:10.14198/jhse.2020.15.Proc4.44

S1476 | 2020| Proc4 | VOLUME 15

C 2020 University of Alicante 


\section{INTRODUCTION}

The current development of technologies allows online consultation, the use of email and access to huge updated databases and other teleprocessing modalities that have become a priority for educational institutions and they are preparing to develop independent learning skills and research, so that a means or technological resource is a form of distribution and presentation of information, an aspect of which the didactic discipline of physical education does not escape (Sánchez, 2013).

The use of technology in Physical Culture and Sports has been moving from mechanical and instrumental positions to systemic (curricular) positions, where it is perceived as one more element of the didactic process.

At the technological level, the budgets of Marqués, 2012; Gértrudix, 2012; Baukal, Ausburn \& Ausburn, 2013, Claros \& Cobos, 2013; Moya, 2013; Aguaded, López, Jaén, 2013; Olanda \& Panach, 2014; Sánchez, 2009, 2013; Bolaño, 2017; Sánchez, Duany \& Pozo 2018, regarding the most distinctive characteristics of Information and Communication Technologies (ICT): interactivity, instantaneity, innovation, high image and sound quality parameters, digitization, automation, interconnection and diversity. Particularly with regard to the didactic - technological conceptions.

In this sense, in the didactic discipline of physical education the means or didactic resources are considered as materials or any type of device designed and elaborated with the intention of facilitating the teaching and learning process or the development of sports training.

Consequently, the definition of means is assumed to the didactic component of the educational teaching process or training unit, as the support of the teaching method, considering all the means (technological, spaces, places of sports interest, environmental routes) that recreate the content from its symbolic or real graphic representation to facilitate the achievement of the proposed objectives (Sánchez, 2009, 2013).

So, the media in this study recognizes the term didactic-technological resource (Sánchez, 2013) that are used by teachers and coaches during the didactic preparation of the subjects, or training unit as vehicles and supports for the transmission of messages both instructive and educational. The contents of the subject are presented to students or athletes in different formats, in an attractive way at certain key moments of instruction.

In this sense, it has been found that knowledge retention (see Figure 1) depends on the route used, the figure shows a comparison of knowledge retention if these were learned orally, visually, or both after $72 \mathrm{~h}$.

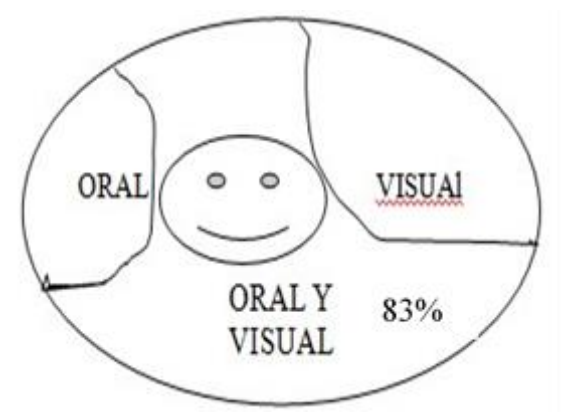

Figure 1. Pathways for retention of knowledge. Source. Sánchez (2013) ICT in sport: Teaching aids in Physical Culture and Sport. 
The researchers of this work consider the interrelation of what is seen, said, discussed, valued and carried out, the retention of the contents reaches $98.5 \%$. It is reflected that the use of didactic-technological resources will be in correspondence with the particularities of age or sports category and its context.

These resources support the course of the knowledge process and educate students or athletes to think rationally and independently, their potentialities not only lie in the instructive, but also in the educational; the effectiveness of which the teacher or coach should worry about, because through their use they stimulate the rules of conduct of students or athletes.

The existence of multimedia, educational software applied to different knowledge sciences is recognized, mostly aimed at primary, middle, and university levels, but in the sports context it is much less. Digital materials have been developed in multimedia format in volleyball, soccer, basketball, but the references that exist in this regard are worked rather predominantly hypertext, interaction is limited, and regarding the conception of the resources used, their didactic treatment is limited.

Hence, the objective of this study focuses on exemplifying the use of a didactic-technological resource in the didactic discipline of physical education in times of pandemic. So that it can be applied without space and time being a limitation.

\section{METHODS}

Based on the research needs, this study responds to an interpretive paradigm. Through qualitative and descriptive methodology, the educational reality is described and interpreted in order to reach the understanding or transformation of said reality, based on the meaning attributed by the people who make it up. In this way, it allows obtaining sufficient information for decision-making and providing knowledge about the environments, attitudes and behaviours that occur in the teaching setting in relation to the teaching modalities (face-to-face, blended and distance) and with the use of ICT as a methodological and didactic resource in the university environment.

This study was carried out with a qualitative methodology, established in case studies through the opinions obtained from teachers, coaches and students. The technique used was observation through the survey. A workshop was held with the characteristic of a group interview. The data was recorded by the evaluators and the information was transcribed to written texts. The sample consisted of 22 professors and 15 students from the Physical Culture career in 2020.

Regarding its reliability, a pilot test was applied in order to verify if the instrument really measures the use of didactic-technological resources in the Didactic discipline of Physical Education, teachers with the same characteristics of the population under study, later Having applied the Cronbach Alpha formula, a reliability of 0.97 was obtained, considering a high level of reliability, which demonstrates the relevance of the instrument for data collection, which allowed its application.

For data processing, descriptive statistics (frequencies and percentages) are used, the variables are on an ordinal scale. Excel was used for data processing. 


\section{RESULTS}

\section{Results of the survey of professors of the Bachelor of Physical Culture career}

The interview was applied to 22 professors (9 instructors, 11 assistants, 2 assistants), belonging to different departments of the faculty, during the 2020 academic year and consisted of seven indicators related to the needs, priorities and gaps in the use of Technology Technologies. Information and Communications in the activities of the didactic discipline of Physical Education.

\section{Indicators}

1. Use of didactic-technological resources in the Didactic Discipline of Physical Education outside the classroom context.

$72.7 \%$ are at a low level regarding the use of didactic-technological resources in the Didactic discipline of Physical Education outside the classroom context and $27.7 \%$ are at an average level. Thus, the conception of the teaching process has not been based on the essentialities of the dynamics of the PDE of higher education, since in general it has been limited to the teaching of the discipline only in person with limitations in blondeness and null remote work, as well as courses or workshops, from a traditional approach. It is evident that there is an intention to direct its development, however, it is appreciated that there is not an adequately clear understanding of the means of how to do it, especially in a consistent way.

\section{Knowledge about Information and Communication Technologies.}

$40.9 \%$ value their level of knowledge about Information and Communication Technologies as low. They recognize or identify ICT with the Intranet and Internet without taking into account other manifestations derived from it, such as interactive multimedia, other didactic-technological resources, discussion forums, Chat, among others. Despite the fact that $36.3 \%$ value that they have a medium level of knowledge and $22.7 \%$ report having a high level, they do not raise the immediate possibilities offered to teacher development in the activities of the Didactic discipline of Physical Education, since they do not take into account collaborative work, constant exchange and updating of information through network communication, both nationally and internationally, exploitation of the network for exchange and consultation about the research carried out by students with colleagues related to their profession, be they students, teachers or other related people. Thus, this situation has a negative influence on the development of the teaching process for the discipline under study in this era, given the needs of university students to access and quickly have a greater volume and diversity of information and communication from the diversity of technological resources.

3. Motivation for developing scientific research activities with the use of ICT. $50 \%$ have a medium level of motivation to develop teaching activities with the use of ICT; and $51 \%$ are motivated to develop activities with the use of ICT. Consequently, it is not possible to systematize search activities through the network by students to quickly access a greater volume and diversity of information that guarantees the timeliness and authenticity of the topics to be dealt with in the discipline.

4. Activities for the exchange of subjects of the discipline of Didactics of Physical Education between students and other colleagues of the profession.

$86.3 \%$ consider as low the activities for the exchange of topics of Didactics of Physical Education between students and other colleagues of the profession through email, forum debates among other resources, and only $13.6 \%$ the considered as a means, which denotes that the technological culture (related to ICT) and what these can promote in the teaching process in relation to information and communication is not enough, therefore, the network is not exploited to search for contents that encourage their cognitive independence, 
as well as the location and processing of reference materials, scientific articles that promote the intention for appropriation and systematization of the contents.

5. Methodological knowledge to use ICT in the teaching activities of the discipline outside the university context.

$100 \%$ of the teachers surveyed consider the methodological knowledge to use ICT in teaching activities in the discipline as low. Consequently, they do not have didactic strategies or methodologies that allow the development of teaching activities outside the classroom context with the use of technological resources. Therefore, the search for up-to-date and novel information about topics to investigate, access specialized sites and virtual libraries is not promoted.

\section{Networking.}

$81.8 \%$ consider that it is very low and $18.1 \%$ consider it to be under networking, (Intranet, Internet) for debate, reflection on research topics of the discipline, therefore the facilities that these media as a resource for communication, through this route, with other students, professors and colleagues in the profession, allowing them to exchange experiences, resources, scientific content of interest and solve research problems that arise in the discipline.

7. Use of the network to communicate investigative tasks of the discipline by students.

The level of use of the network to communicate investigative tasks about the contents of the discipline by students is at very low and low levels, which indicates that there is limited use of didactic-technological resources (email, forums of discussion, interactive multimedia, among others) in order to disseminate and socialize both tasks and the results of the investigations carried out.

In the learning preferences indicator, $57 \%$ of students expressed that ICT in its multimedia manifestations, virtual platforms, and other technological resources are the most preferred means of studying, $86 \%$ are prepared to use tutorials, videos, Moodle platform, YouTube, WhatsApp, Messenger, Telegram and 93\% consider that a technological didactic resource would be of support not only for the discipline of Didactics of Physical Education but for all.

Regarding the types of content, $59 \%$ of the students expressed a preference for videos as a means of learning the elements and execution of the technique, in physical preparation linked to audio from the explanation and demonstration by the Teacher.

\section{Approaches generated from the workshop}

Teacher 1 . The possibilities that networks offer for communication not only generate demands for the adaptation of the educational processes that take place within the educational system, but the educational impacts of electronic communication go beyond said system.

Professor 2. This will become the main function of the university because it is at the heart of the use, selection and organization of information, which will be one of the most important aspects of the information society.

Teacher 3. To put into practice the renewal of educational ideas (of the objectives, of the content, of the methods, of the pedagogical techniques) to make them more in line with the society in which the student is immersed and in which The technologies form an important part of their social environment, the educational objectives must tend to adapt the student to this changing society that he has had to live. 
Professor 4. The university must become aware of these new challenges and provide alternatives in terms of research modalities in the disciplines. It is useless to replace the old media with new technologies without another change in the educational systems. In order for the university to adapt to continuous cultural changes, it must modify its current positions in two fundamental aspects: knowing how to take advantage of what has been proposed: the resources didactic-technological that it offers and train students for the correct reception and assimilation of the messages that said media transmit.

Teacher 5. Among all the changes that ICTs cause in teaching activities, as has been stated, the change in the role of the teacher is one of the most important. As a new student-user of the training is configured, the role of the teacher also changes in an environment rich in ICT.

Researcher of the study: It is not advocating for an expert professor in internet browsing, telecommunications expert, etc., but for a professional who masters the basic skills related to telecommunications networks, who is attentive to the changes that occur in society and with a great command of communication.

And, the networks, in addition to demanding changes in the ways of acting of professionals, contribute to face them. Along with the possibilities that the networks offer in terms of resource bank etc. There is also the issue of professional development from updating and knowledge of resources to collaborative work, in the creation of common materials, it is verified that the dissemination of information is enriching to the extent that the user is trained to understand it and motivated to read or use it.

Awareness-raising action: it is necessary since this method uses participation and not only the receipt of information. The type activity, in this sense, is work in short-term seminars, where, above all, the treatment of theoretical foundations, group work, practical work and the exchange of opinions between teachers and students and other subjects.

The university and the professor are no longer sources of all knowledge and the professor begins to act as a guide for students to facilitate the use of resources and tools they need to explore and develop new knowledge and skills, and to act as a manager of diversity of technological didactic resources and accentuate their role as counsellor.

For the exemplification of the use of the didactic-technological resource of the disciplines of said career, the contents of the volleyball theme II of the Didactic Discipline of Physical Education are selected, which belongs to the exercise of the profession, and will be linked to the activity of the graduate, this will guarantee the fundamental modes of action, contemplated in the Professional Model of the Bachelor of Physical Culture career. We work on topic II: "The technique and tactics of the game. Team management. Organization and competition regime. Conditional and coordinative capacities".

Didactic-technological resource in the didactic discipline of physical education in times of pandemic

- Professors and collaborators of the PDE must be systematically surpassed in the areas: technological (with ICT) and research, to guarantee their constant updating and in this way they can use the most appropriate method, as well as to satisfactorily perform their tasks and roles as counsellors of students in the teaching process.

- The students of the career recognize the possibilities that ICT can offer them for their professional performance and at least have a mobile phone, tablet, or computer with connection. 
Other aspects necessary for the application of the resource are: stability in the operation of the university intranet and incorporate Internet access; Students, teachers and other subjects who collaborate with the PDE should make greater use of networking, both in communication with other colleagues, as well as in the search and management of wide and varied information, as well as resources and alternatives when faced with any problem and thus optimize the execution of teaching tasks.

\section{Requirements}

- Guarantee in the PDE in the subject of volleyball the adequate availability and diversity of didactictechnological resources (the program of the discipline and the subjects, the objectives, the study guides, the materials with the contents, the exercises must be digitized self-assessment, videos recorded from the screen in real time, conferences and seminars, through presentations. Audio associated with the videos to reinforce the teaching of the contents).

- Guarantee the digital literacy of students (and teachers ... and families ...), Marqués, 2012.

- Systematic improvement is ensured: technological (referring to ICT) and research by teachers.

\section{Diagnosis}

The diagnosis that is made at the beginning of the topic (consisting of a reflection and awareness workshop with the group of students), makes it possible to detect their knowledge to face teaching activities, using ICT, which promotes following a logic for collaborative construction.

For students, the diagnosis will be aimed at knowing their degree of preparation to be able to use ICT, in the teaching process, particularly in relation to:

- Browse the Web, which means: knowing the local Web and looking for information on it; use professional program packages with the contents that are taught in the discipline Teaching physical education; use e-mail: answer emails, send messages, attach files to the message, use different technological tools such as self-learning means (interactive multimedia, Web pages, tutorials, simulators, interactive platforms), search for information on the Internet.

- Competences to develop the search for updated content of the discipline, which means: identifying the main sources of information on the Internet; search and review localized information; carry out the critical analysis of the selected information, carry out the registration and organization of the information; and the communication of information (Work on the Web with Databases and Bibliographic Managers).

Methodological preparation of teaching activities for the application of the volleyball didactic-technological resource

- The objectives of the subject are specified, as well as the skills that are intended to be developed with it (taking into account what is revealed in the diagnosis and characterization of the group of students: the most advantaged and those who need the most help) are also given to know the rules for participation and evaluation.

- Scientific research activities are planned and organized with the use of didactic - technological resources, as well as the most conducive methods for the chosen topic, in correspondence with its objectives.

- A (systematic) evaluation system is planned and organized in the course of teaching activities on the subject, which allows to gradually detect the fulfilment of its objectives and the appropriation of knowledge and the development of skills in students. 


\section{Use of the resource}

Teacher: begins the initial activity (not in person) with a seminar in a space where only the time to be connected has been set, once everyone is online, students are presented with different topics related to volleyball that are related in the contents of the discipline, so that the latter select one of them based on their intention, their interests and motivations.

In addition, the teacher explains to the students the importance of the use of didactic - technological resources during the teaching process, as a key element in their professional training. At the same time, it socializes the topics proposed for the development of the contents and the addresses where the digitized materials located on the network are found, with the aim of making an analysis, assessment and interpretation of various topics, such as: Analysis and Evaluation of the Volleyball, Speed training in volleyball, Collective behaviour, Talent selection, Sports training, Technical and tactical preparation.

Student: accesses and has updated articles, and through the resource is connected to internationally recognized sites, to sports magazines that achieve the selection of topics, not only those proposed by the teachers, but also those selected based on their need to deepening; determines their interests, motives, needs, to choose and investigate the subject, shares the criteria with other students and teachers about the need for their adequate theoretical and practical preparation.

Teacher: forms small groups of students with related themes, guides that discussions can take place synchronously or asynchronously (WhatsApp, Messenger, Telegram, among others).

\section{Promote accessibility and availability of content}

Teacher: guides the exploration and determination of the content (where the student must verify its existence and its objectivity from the way it is manifested), for which it indicates the review of documentary sources that provide figures, data, assessments about of the results obtained so far, guides the search in virtual libraries, encyclopaedias, databases, Web pages, interactive multimedia, representations and simulations that facilitate the understanding of various concepts, addresses of internationally recognized sites that respond to the object of the profession, e-mail addresses of specialists (or other subjects) who investigate the chosen topic.

Student: through communication, both synchronous and asynchronous with teachers, students and specialists related to the subject, they determine the conditions in which the subject is mostly manifested, analyse how technical-tactical elements have been investigated, for example, by other authors, which requires the new way of approaching it to guarantee the novelty and originality of the research and use the didactic - technological resources, identifying the most recognized authors.

\section{Promote the construction of new scientific content from collaborative work}

Teacher: guides the identification of concepts and keywords and the area to which the research object belongs.

Student: selects, organizes, stores information, analyses and critically evaluates existing theories, exchanges and shares criteria and judgments with others, in person or through the network (discussion forums, electronic talks, email), investigates bases of data, specialized search engines, archives with highly current scientific publications. 
Teacher: guides the study independently of the different technical-tactical elements, through videos complementing it with the video of a complete game, as well as game simulations for analysis.

Student: to be able to integrate all the content, they must perform the following actions: compare the technical-tactical elements observed independently with respect to the elite game shown in the video; assess the development of these elements in the game; exchange criteria and experiences through the network, with specialists on the subject.

Teacher: guides them to express the interpretation made through a summary and send it by collective email, which allows it to be seen by all.

The expectation of discovering what is new, of accessing the content through the didactic-technological resources, generates a motivational process (intentionality) in the student that compels him to resolve the contradiction between his assumptions and the new information that is incorporated; at the same time, to the extent that it builds, it is stimulated and motivated to continue deepening the content.

Teacher: guides the preparation of a set of technical-tactical actions after having observed the video found in the interactive multimedia of the subject and presentation of different solutions to the situations that are generated and guides the following activities to the students:

a) Investigate how the technical-tactical elements have been worked from the beginning of the sport's creation to the present,

b) What are the main modifications if they have occurred?

c) Compare the results obtained from the Honduran team with other international teams and assess the incidence of these elements.

Student: asks and answers questions between virtual peers or in person, performs interpretations mediated by experience that can be achieved through electronic talks, email, discussion forums, interactive platforms. Then, it forms a writing that summarizes the historical behaviour of its object.

Student: elaborates the observation guide based on the proposed indicators, assesses and interprets the results obtained, compares the results with other students, is motivated towards the search for the possible causes of errors or inadequacies found in the development of skills motor sports. In addition, it develops other actions among which are:

- Share concerns and proposals for possible solutions with experts or specialists through the network; processes the information obtained through sustained communication; collaborates, shares criteria, in addition to enriching and nourishing themselves with the knowledge and experiences contributed by other subjects, which enhances the previous scientific content when relating it to the new ones to acquire meaning and meaning; proposes other alternatives for the development of technical-tactical elements.

- Prepares a report about the research that he presents in the classroom through a Power Point presentation or through the discussion forum, where he shows the relationships between the observed facts, how their results and interpretations agree or not with the works previously published in different sites and as they are enriched or improved a scientific activity is proposed for its presentation.

Professor: The best works are published in selected journals, included as study material and are posted on the web. 
The actions described affect the improvement not only as a teacher, player, coach, but also contribute to enhancing the active participation of students in solving problems of their profession and manage to give a meaning and sense of transformation to the use of ICT in the development of the teaching process.

From the fulfilment of the evaluation criteria, the students will have created the necessary skills to, independently and flexibly, undertake the teaching activity in which they have to go through all the actions that they have previously described. It must establish conclusions that show the advisability of the use of ICT with a meaning and sense of transformation for the teaching process of the Didactic discipline of Physical Education.

\section{DISCUSSION}

In the activity of Physical Culture and Sports, the use of teaching aids receives a strong boost, which are considered as materials or auxiliary aids and constitute an important component of the teaching-learning or sports training process as they allow the appropriation of knowledge, the development of the skills and abilities of students or athletes, that is why, during physical education classes and specifically in practical sports classes, the use of the media are requirements for the development of these activities (Sánchez, 2013).

The use of ICT within the teaching-learning process must account for Pedagogical approaches (Marqués, 2012; Olanda \& Panach 2014; Sánchez R. 2009, 2013; Bolaño, 2017; Sánchez, Duany \& Pozo 2018; Bolaño, 2017); that follow: learning as an active process in which the subject has to carry out a series of activities to assimilate the informational content that he receives from the variety of existing technological resources. As you repeat, reproduce, or relate the knowledge, you will perform repetitive, reproductive, or meaningful learning.

The foregoing is corroborated when the teacher works with appropriate means such as photos, videos, has more time to organize and carry out work on individual differences and allows students / athletes to carry out a greater exercise, and its incidence, in the cognitive, affective and psychomotor dimensions, which facilitate achieving significant learning, the effectiveness is different if, on the contrary, there is excess spoken language on the part of the teacher or coach to explain a physical exercise or technical element of a sport.

Specifically, in the case of videos, it is generally used to show content that is difficult to achieve or represent during training. They can be used to show a game situation that occurred in an international championship difficult to explain with the use of words or static images, and that it is also impossible to transfer athletes or students to the venue live. It can be used to record the executions of technical and tactical elements during sports preparation and then the team members evaluate themselves, evaluate each other, and be evaluated by the teacher. Video, despite being very effective, is less economical therefore its use must be well founded.

Therefore, it is convenient that the activities of the programs are in line with current pedagogical trends, so that their use not only in classrooms and sports environments but in other contexts causes a methodological change in this regard.

\section{CONCLUSIONS}

The results of this study referred to the exemplification of the use of a didactic-technological resource in the Didactic discipline of Physical Education in times of pandemic, are in the process of continuous improvement, 
the thematic contents of the Didactic discipline of Physical Education are created considering the curricular area, the group of students, the personal resources that both teachers and students have, the specific content of the volleyball subject, the teacher's own technological preparation, among others.

Based on the diagnosis made, it is necessary that in the sports educational field awareness is gained that the use of these new resources will impose marked transformations in the configuration of the pedagogical process, with changes in the roles that the various actors have been playing.

Thus, new tasks and responsibilities await students and teachers, coaches, athletes among others, the former will have to be more prepared for decision-making and the regulation of their learning and the latter to design new learning environments and serve as tutor of the students when moving from a unidirectional model of training where he is the fundamental carrier of knowledge, to other more open and flexible ones where the information is found in large databases shared by all and where time and space cannot. become barriers to achieving learning.

\section{REFERENCES}

Aguaded, López y Jaén, (2013). University e-Portfolios as a New Higher Education Teaching Method. The Development of a Multimedia Educational Material (MEM). Revista de Universidad y Sociedad del Conocimiento (RUSC). Vol. 10, n. ${ }^{0}$ 1págs. 7-28. UOC. https://doi.org/10.7238/rusc.v10i1.1333

Baukal, Ausburn, Ausburn, (2013). A Proposed Multimedia -Cone of Abstraction: Updating a Classic Instructional Design Theory. Journal of Educational Technology. https://doi.org/10.26634/jet.9.4.2129

Bolaño, (2017). Uso de Herramientas Multimedia Interactivas en educaciónpreescolar. En Revista Didáctica, Innovación y Multimedia, núm. 35. Retrieved form: http://dimglobal.net/revista35.htm

Claros y Cobos (2013) del vídeo educativo a objetos de aprendizaje multimedia interactivos: un entorno de aprendizaje colaborativo basado en redes sociales. Revista Tendencias Pedagógicas № 22 Universidad Autónoma de Madrid.

Gértrudix (2012). Convergencia multimedia y educación. Aplicaciones y estrategias de colaboración en la Red. Revista ICONO14 Revista Científica De Comunicación Y Tecnologías Emergentes, 4(1), 125-142. https://doi.org/10.7195/ri14.v4i1.401

Marqués (2012) Impacto de las TIC en la educación: funciones y limitaciones. Revista de investigación Editada por Área de Innovación y Desarrollo, S.L.

Moya (2013) De las TICs a las TACs: la importancia de crear contenidos educativosdigitales Revista Científica Didáctica, Innovación y Multimedia (DIM). Retrieved from: http://dim.pangea.org/revistaDIM27/docs/AR27contenidosdigitalesmonicamoya.pdf

Olanda y,Panach (2014) Aprendizaje colaborativo basado en tecnologías multimedia. A: JENUI. "XX Jornadas de Enseñanza Universitaria de la Informática". Oviedo: Universidad de Oviedo. Escuela de Ingeniería Informática. Retrieved from: http://hdl.handle.net/2099/15501

Sánchez (2009). Las Tecnologías de la Información y las Comunicaciones en la Dinámica del proceso de formación para la investigación científica en la Educación Superior. (Tesis de doctorado inédita). Universidad Oriente. Santiago de Cuba, Santiago de Cuba, Cuba.

Sánchez (2013).Las TIC en el deporte: Los medios de enseñanza en la Cultura Física y el Deporte. Editorial Académica Española (16 juin 2013). ISBN-13 : 978-3659062469.

Sánchez, Duany y Pozo (2018). Método colaborativo investigativo para la gestión del contenido en diferentes áreas del conocimiento. Revista innova ITFIP, 2 (1), 6-13. 
Laínez-Bonilla, et al. / Didactic resources for physical education in times of pandemic JOURNAL OF HUMAN SPORT \& EXERCISE

\section{(c) 7 (i) (9)}

This work is licensed under a Attribution-NonCommercial-NoDerivatives 4.0 International (CC BY-NC-ND 4.0).

VOLUME 15 | Proc4 | 2020| S1487 